\title{
Evaluate the Relevance of Strategic Management Accounting in the Contemporary Global Organization
}

\author{
Ali Abdulridha Jabbar \\ Department of Accounting by IT / Cihan University- sulimanya / Kurdistan region, Iraq
}

\begin{abstract}
This research is intended to know the intention of bringing a new kind of description to the much misunderstood process of strategy formation in organizations. the usual definition of "strategy" encourages the notion that strategies, as I recognize them ex post facto, are deliberate plans conceived in advance of the making of specific decisions. By defining a strategy as "a pattern in a stream of decisions", the research strategy formation in a broad descriptive context. Specifically, I can study both strategies that were intended and those that were realized despite intentions the last few years have seen a growing interest in strategic management accounting (SMA). That strategy formation over time appears to follow some important patterns in organizations, notably life cycles and distinct change-continuity cycles within these; and that the study of the interplay between intended and realized strategies may lead us to the heart of this complex organizational process. at least in certain contexts. A strategy is not a fixed plan, nor does it change systematically at prearranged times solely at the will of management.
\end{abstract}

Keywords: Strategic Management Accounting, Management Accounting, Evaluation and Organizations

\section{Introduction}

Strategic Management Accounting (SMA) came to prominence in the late 1980s as one of the range of new techniques and approaches designed to restore the lost relevance of management accounting. It did so principally in the UK, with Bromwich as one of its main academic advocates at that time (Bromwich, 1988, 1990, 1991, 1992; Bromwich and Bhimani, 1989, 1994). The literature on strategy formation is in large part theoretical but not empirical, and the usual definition of "strategy" encourages the notion that strategies, as we recognize them ex post facto, are deliberate plans conceived in advance of the making of specific decisions. By defining a strategy as "a pattern in a stream of decisions", we are able to research strategy formation in a broad descriptive context. Specifically, we can study both strategies that were intended and those that were realized despite intentions the last few years have seen a growing interest in strategic management accounting (SMA). Casual observation of changes in accounting curricula suggest that courses of study entitled 'Strategic Management Accounting' are becoming commonplace in tertiary and professional management accounting education syllabi. A journal issue was dedicated to SMA (Management Accounting Research, 1996) and there is a growing number of books that include 'strategic management accounting' in their title Despite in addition to pursuing these objectives, the study offers an original distillation of a set of SMA practices. At present such a list is not available.

The term SMA has a longer history, however, having been introduced into management accounting some years earlier by Simmonds $(1981,1987)$. Management accountants could assess the strategic impact of internal information and collect information about the position of competitors, 'synthesizing the resultant Information and making it available to the strategic process this project critically evaluates the whole notion of strategic management accounting. It argues that the techniques and elements of strategic management accounting may in many cases already be found in firms. However, the information may not be quantified in accounting figures, and may not be collected and used by management accountants. Rather, the techniques for gathering and using information necessary for the operational management of firms. That strategy formation over time appears to follow some important patterns in organizations, notably life cycles and distinct changecontinuity cycles within these; and that the study of the interplay between intended and realized strategies may lead us to the heart of this complex organizational process.

\section{Management Accounting}

Recent literature, both academic and professional, is flush with commentaries on the changing nature of management accounting practice (Bhimani, 1996; Shields, 1992). These are interesting and extremely challenging times for management accounting, its academics and its practitioners. The 'New Economy' demands change - or so it appears. Particularly since the publication of Relevance Lost, academics, accountants in business and consultants have sought to develop new and so-called 'advanced' management accounting techniques and new management accounting systems - a management accounting that meets the information requirements of business managers in today's global, technology driven world. In recent years, many firms have 
been experiencing significant change in their organizational designs, competitive environments and information technologies. For instance, business environments exhibit a variety of structures and processes - including flat and horizontal organizational forms, multidimensional matrix structures, networks of 'virtual' organizations and self-directed work teams (Lukka and Shields, 2001). Also, advances in information technology have driven innovation and change in the collection, measurement, analysis and communication of information within and between organizations, facilitated in particular by such technologies as enterprise resource planning systems, ecommerce, the internet, electronic data interchange and electronic meetings (Atkinson et al., 1997). To many observers, such broad change implies a need for management accounting to change also.

Management accounting is not new in any sense of the world. The origins of modern management accounting can be traced to the emergence of managed, hierarchical enterprises in the early nineteenth century. The Industrial Revolution in the early nineteenth century result either emergence of a factory system that dramatically changed the production process. Several taxonomies of strategic positioning have been developed in the business strategy literature. The relationship between the strategic position chosen by a firm and the expected emphasis on management accounting is examined in the second part of this section: 'Accounting for strategic position

\section{Strategic Management Accounting}

The term strategic management accounting (SMA) has been used to describe the process of 'provision and analysis of management accounting data about a business and its competitors for use in developing and monitoring business strategy'.1 We may illustrate the basic ideas of SMA by looking at one of the leading retailers in the United Kingdom, Tesco, which has tailored its key performance indicators to the economics of its business. For example, rather than maximize EVA, Tesco has realized that its main fixed assets are its stores. With this type of asset base, the company aims to reduce the cost of building good quality new stores through strategic partnering with construction companies. In order to check its market positioning, the company is constantly monitoring the prices of its merchandise relative to the prices charged by its main competitors. As well as promoting customer loyalty, it uses its store card as a database for targeting the specific needs of individual customers as revealed through their purchase patterns. It also keeps a close eye on non-financial indicators such as the length of queues at the check-outs. Tesco's approach in linking its goals and its management information systems demonstrates many of the principles of SMA. The company has decided how it is going to compete, reviewed its internal and external operations and chosen key performance indicators that enable it to monitor the development of its chosen business model. The search for data is driven by decision needs rather than by what is simply easily available or fashionable (such as EVA).

\section{Strategy Themes in Management Accounting}

Successfully integrating management accounting and strategy themes and concepts provides an exciting and potentially insightful prospect for accounting scholars and researchers. It is not surprising, therefore, to find a number of examples of this in the recent literature of management accounting. Before discussing strategic management accounting as an attempt to integrate management accounting and marketing, it is instructive to outline the reservations that we have regarding some of the more robust attempts to interface management accounting and the strategy literature. The three examples of such work selected for critique are: Simons' early work on the relationship between firm strategy and control system; Kaplan and Norton's subsequent work on the balanced scorecard concept as the enabling mechanism that links firm strategy with action; and Shank and Govindarajan's work in developing a strategic cost management framework (Guilding. Cravens and Tayles, 2000).

Simon's principal contributions to the development of a management accounting strategy interface were presented in a pair of papers published in Accounting, Organizations and Society on the relationship between firm strategy and control system. In the first paper, the relationship between firms' accounting based control systems and their business strategies is explored within a contingency theory framework. Simons is heavily reliant typology of generic business strategies. Three such strategies are identified: the defender strategy necessitates the pursuit of cost leadership and a concern with quality and customer service, and is characterized by a limited extent of product and market development. The prospector strategy is characterized by a succession of market offerings and the continued pursuit of new market opportunities, and is heavily reliant on creativity and innovation. The hybrid analyzer strategy combines elements of the other two. Using both interview and questionnaire data, Simons demonstrates that firms embracing a defender strategy use their accounting control systems less intensively than those adopting a prospector strategy for whom forecast data, setting tight budget goals and continuously monitoring outputs is of great importance. In his 1990 paper, Simons exchanges a contingency perspective for an exercise in model building based on detailed case analysis. The strategy content of the paper is now significantly enhanced by the inclusion of additional typologies of business strategy discussion of the difference between business strategy and corporate strategy; and more fundamentally, the 
observation that it is necessary to consider strategy as process. Consequently, rather than being concerned with the implications that business strategy has for control systems, Simons focuses on the ways in which strategy and management control systems interact, thereby rejecting the position that strategy. (Roslender and Hart. 2002).

\section{The Evolution of Strategic Management Accounting}

Strategic management accounting (SMA) came to prominence in the late 1980s as one of the range of new techniques and approaches designed to restore the lost relevance of management accounting. It did so principally in the UK, with Bromwich as one of its main academic advocates at that time. What differentiated SMA from many parallel developments was its external orientation, hence Bromwich and Bhimani's observation that it provided a means of releasing management accounting from the factory floor. Using the term strategic to name the approach was also intended to convey that SMA incorporated a longer term outlook, as well as a broader emphasis than the greater part of management accounting. This was consistent with Bromwich's initial identification of SMA as offering a higher order of management accounting. For these reasons it was not difficult to recognize in SMA a potentially important departure for the practice of accounting to management. The term SMA has a longer history, however, having been introduced into management accounting some years earlier by Simmonds. It was again used to identify and externally oriented approach that entailed collecting and analyzing data on costs, prices, sales volumes, market shares, cash flows and resource utilization, for both a business and its competitors. What was being sought was some indication of the relative competitive position of a business in an industry. Within this competitor position analysis framework, less importance was placed on financial accuracy than upon deriving insights that might inform the future strategy of a business.

In reformulating SMA, Bromwich was able to draw on a wider range of relevant insights. Porter's work on business strategy identified three generic strategies: cost leadership; product differentiation; and focus, each of which had different implications for both management and accounting. Like SMA, target costing also exhibited a strong external emphasis, not simply on competitors but also on customers and the marketplace. In addition, the economic theories of Lancaster, on product attributes and Baumol, on contestable markets enriched the mix, something that was evident in Bromwich's (1990). (Roslender and Hart, 2003).

\section{The Management Accounting Systems and Their Development}

All the senior management in the Company is involved in the strategic planning process. This includes the director responsible for the management accounting function. As such there is no definitive contribution made by a management accounts department, but this does not mean that management accounting techniques are not employed. The management accounting function provides traditional historical data on previous production runs and costs which are used as an initial starting point when pursuing new customers. This use of historical cost data is a first stage in using management accounting strategically (Dixon, 1998). On a daily, weekly, monthly or ad-hoc basis, the management information system aids the accounts function to produce information for management, be it on cost behavior or investment appraisal. The finance function is also responsible for producing monthly management reports that include such salient figures as the profit and loss account, balance sheet, sales analysis, overheads analysis, productivity data and recovery analysis.

\section{Strategy Formulation}

In order to ensure that it remains competitive, the Company sets targets or performance indicators by which it monitors its performance. These targets are based on both the internal Company strategy and comparisons with key competition. The Company takes the view that failure to monitor performance against external standards and, in particular, key competition, is likely to lead in the long term to failure to compete effectively and lose market share. In terms of non-financial monitoring, the Company uses a number of measures such as Quality Assurance, Supplier and Purchasing information, Sales and Marketing information and Working Capital and Asset Management Performance as the Company pursues its narrow target focus differentiation generic strategy it believes that only through ongoing reviews and analysis will it be able to sustain its market position. This is critical in the mature market in which it operates, as failure to review strategies and objectives as external circumstances demand means that the Company's response to a changing environment would be impaired and competitive advantage would be lost. The Company's strategic intent is: It is clear from this statement of strategic intent that the Company's objectives encompass strategies that are not only financial. Strategies relating to human resources, hygiene factors and service standards are high on the agenda and are seen as a route to sustaining competitive advantage. The Company believes that over-emphasis on measuring strategic objectives against financial criteria would result in the organization losing sight of other important performance indicators. In addition, the strategies will be too closely related to short term profit 
maximization, at the expense of long term improvements necessary to compete effectively. (Accounting for Strategic Management: A Practical Application)

Strategy is not formulated and implemented solely by top management. There are likely to be several interest groups within an organization, each having its own set of stakeholders with whom it acknowledges relationships and whose expectations it considers. Strategy emerge out of conflict between these 'networks of interacting stakeholders pursuing individual interests.

\section{Evaluate of Strategic Management Accounting in The Organizations}

What are strategies and how are they formed in organizations? A large body of literature, under the title of strategy formulation in the private sector, and policy making in the public sector, addresses the question of how organizations make and interrelate their significant (that is, strategic) decisions. (Mintzberg, 1973).

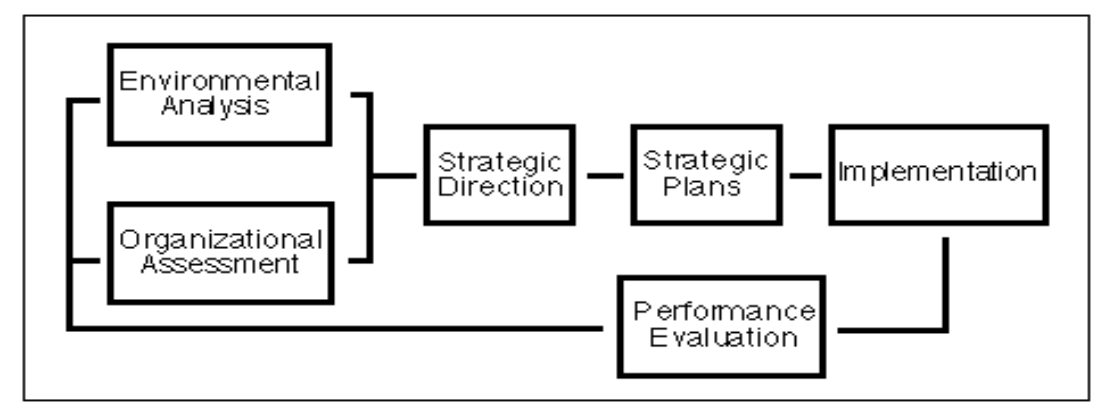

has suggested that a good deal of this literature falls distinctly into one of three theoretical groupings, or "modes". The planning mode, comprising the largest body of published materials and in the tradition of both management science and bureaucratic theory, depicts the process as a highly ordered, neatly integrated one, with strategies explicated on schedule by a purposeful organization .In sharp contrast, the adaptive mode, in the public sector and in the context of business, depicts the process as one in which many decision-makers with conflicting goals bargain among themselves to produce a stream of incremental, disjointed decisions. And in some of the literature of classical economics and contemporary management, the process is described in the entrepreneurial mode, where a powerful leader takes bold, risky decisions toward his vision of the organization's future Some interesting research has been undertaken to put the theory into empirical context, for example, Allison's development of three models to explain policy making perceptions during Collins and Moore's description of the entrepreneurial personality (Collins, 1970), and Bowman's investigation into strategic effectiveness (Bowman, 1976) .But most of the literature remains theoretical without being empirical, and the contradictions among these three modes remains to be investigated. This paper presents the results of the first stage of a research project begun in 1971, and continuing, to study patterns in the process of strategy formation. The first section describes the term "strategy", and shows how the definition leads naturally to the choice of a research methodology. This methodology is described in the second section. A third section then describes briefly the results of the formation of strategies in two organizations, and a final section presents some theoretical conclusions about strategy formation that arise from these results.

Mintzberg (1978) was one of the first to point out that the strategic planning literature ignored other types of strategy formation. Some strategies do arise from strategic planning. This is achieved in purposeful organizations with highly ordered, neatly integrated processes. Planned strategies may also be achieved in entrepreneurial firms, where powerful leaders make bold, risky decisions to implement their visions. However, some organizations may consist of many decision-makers with conflicting goals. As they bargain among themselves they may produce incremental, disjointed decisions. Strategies will form out of this adaptive process. Mintzberg, 1978). thus made a distinction between strategy formulation and formation. He defined strategy formulation as the long-range planning by leaders of organizations

Strategy formation, on the other hand, he defined as the result of interplay between the environment, the organizational operating system and the organization's leadership. The environment is changing continuously but irregularly; the organizational operating system seeks stability; and the leadership mediates between the two, trying to achieve both organizational stability and the ability to adapt to change. A few words on gestalt strategies are in order, since they appear frequently in Organizations. First, they seem to develop at one point in time, most frequently when the organization is founded. That is when bureaucratic momentum is weakest, leadership typically strong (entrepreneurial), and environments rather tolerant. In contrast, achieving a gestalt strategy is difficult in an ongoing organization, which has a great deal more bureaucratic momentum. No doubt because both faced environments beginning to settle down after periods of great turbulence that had severely disrupted their bureaucratic momentum. Second, gestalt strategies seem to be associated with single, 
powerful leaders (Lord, 1996). This is especially true of the two periods mentioned above. Perhaps the sophisticated integration called for by such strategies can be effected only in one mind. The development of a gestalt strategy requires innovative thinking, rooted in synthesis rather than analysis, based on the "intuitive" or inexplicit processes that have been associated with the brain's right hemisphere (Ornstein, 1972). Thus we are led to hypothesize that gestalt strategies are the products of single individuals, and only appear in organizations with strong leadership, in effect, those that use the entrepreneurial mode. It is difficult to imagine one coming out of a decentralized organization, unless all the decision-makers follow the conceptual lead of one creative individual.

\section{Conclusion}

This project has been written with the intention of bringing a new kind of description to the much misunderstood process of strategy formation in organizations. A few descriptive studies-two of which are reported here-constitute a limited data base, but they do call into question a number of assumptions about the process, at least in certain contexts. A strategy is not a fixed plan, nor does it change systematically at prearranged times solely at the will of management. The dichotomy between strategy formulation and strategy implementation is a false one under certain common conditions, because it ignores the learning that must often follow the conception of an intended strategy. Indeed, the very word "formulation" is misleading commonly refer to as "strategies" many patterns in organizational decisions that form can be risky because the plans may tend to become actualized, whether needed or not. And so too can it sometimes be risky to make strategy explicit, notably in an uncertain environment with an aggressive bureaucracy. In general, the contemporary prescriptions and normative techniques of analysis and planning and the debate that accompanies them-seem unable to address the complex reality of strategy formation. To tell management to state its goals precisely, assess its strengths and weaknesses, plan systematically on schedule, and make the resulting strategies explicit are at best overly general guide-lines, at worst demonstrably misleading precepts to organizations that face a confusing reality. There is perhaps no process in organizations that is more demanding of human cognition than strategy formation. Every strategy-maker faces an impossible overload of information (much of it soft); as a result, he can have no optimal process to follow. The researcher or management scientist who seeks to understand strategy formation is up against the same cognitive constraints, but with poorer access to the necessary information. Thus he faces no easy task. But proceed he must, for the old prescriptions are not working and new ones are badly needed. These will only grow out of a sophisticated understanding of the rich reality of strategy formation, and that will require an open mind, recognition of how little we really know, and intensive, painstaking research.

\section{References}

[1]. Atkinson, P. M., \& Tatnall, A. R. L. (1997). Introduction neural networks in remote sensing. International Journal of remote sensing, 18(4), 699-709

[2]. Guilding, C., Cravens, K. S., \& Tayles, M. (2000). An international comparison of strategic management accounting practices. Management Accounting Research, 11(1), 113-135.

[3]. Lord, B. R. (1996). Strategic management accounting: the emperor's new clothes. Management Accounting Research, 7(3), 347366.

[4]. Mintzberg, H. (1973). Strategy-making in three modes. California management review, 16(2), 44-53.

[5]. Mintzberg, H. (1978). Patterns in strategy formation. Management science, 24(9), 934-948.

[6]. Roslender, R., \& Hart, S. J. (2002). Integrating management accounting and marketing in the pursuit of competitive advantage: the case for strategic management accounting. Critical Perspectives on Accounting, 13(2), 255-277.

[7]. Roslender, R., \& Hart, S. J. (2003). In search of strategic management accounting: theoretical and field study perspectives. Management accounting research, 14(3), 255-279.

[8]. Simmonds, K. (1981), "Strategic management accounting", Management Accounting, Vol. 59 No. 4, pp. 26-30.

[9]. Simons, R. (1987), "Accounting control systems and business strategy: an empirical analysis", Accounting, Organizations and Society, Vol. 12 No. 4, pp. 357-74.

[10]. Bromwich, M., 1988. Managerial accounting definition and scope-from a managerial view. Manage. Account. (UK) 66 (8), 2627.

[11]. Bromwich, M., 1990. The case for strategic management accounting: the role of accounting information for strategy in competitive markets. Account. Organ. Soc. 15 (1), 27-46.

[12]. Bromwich, M., 1991. Accounting for strategic excellence. Working paper, Department of Accounting and Finance, London School of Economics and Political Science.

[13]. Bromwich, M., 1992. Strategic management accounting. In: Drury, C. (Ed.), Management Accounting Handbook. ButterworthHeinemann, London

[14]. Bromwich, M., Bhimani, A., 1989. Management Accounting: Evolution not Revolution. CIMA Publications, London.

[15]. Bromwich, M., Bhimani, A., 1994. Management Accounting: Pathways to Progress. CIMA Publications, London.

[16]. Bowman Jr, V. J. (1976). On the relationship of the Tchebycheff norm and the efficient frontier of multiple-criteria objectives. In Multiple criteria decision making (pp. 76-86). Springer Berlin Heidelberg.

[17]. Collins, 0. AND MOORE, D. G. (1970). The Organization Makers, Appleton-Century-Crofts, New York.

[18]. Dixon, R. (1998). Accounting for strategic management: a practical application.Long Range Planning, 31(2), 272-279.

[19]. Lukka, K., \& Shields, M. (2001). Management accounting: Innovations in practice and research. CIMA Research Update, 2.

[20]. ORNSTEIN, R. E. (1972). The Psychology of Consciousness, Freeman, San Francisco, Calif., 1972.

[21]. Shields, M.D., Young, S.M., 1992. Effective long-term cost reduction: a strategic perspective. J. Cost Manage. Spring, 16-30.

[22]. Bromwich, M., A. Bhimani, and A. (1981). Hopwood. "British Accounting Theory: A Comparative Study." London: Pitman. 